\title{
Clinical Findings and Demographic Factors Associated With ICU Admission in Utah Due to Novel 2009 Influenza A(H1N1) Infection
}

\author{
Russell R. Miller III, MD, MPH; Boaz A. Markewitz, MD, FCCP; Robert T. Rolfs, MD, MPH; \\ Samuel M. Brown, MD; Kristin K. Dascomb, MD, PhD; Colin K. Grissom, MD, FCCP; \\ Michael D. Friedrichs, MS; Jeanmarie Mayer, MD; Eliotte L. Hirshberg, MD; \\ Jamie Conklin, MD; Robert Paine III, MD; and Nathan C. Dean, MD, FCCP
}

\begin{abstract}
Background: Novel 2009 influenza $\mathrm{A}(\mathrm{H} 1 \mathrm{N1})$ infection has significantly affected ICUs. We sought to characterize our region's clinical findings and demographic associations with ICU admission due to novel $\mathrm{A}(\mathrm{H} 1 \mathrm{N1})$.

Methods: We conducted an observational study from May 19, 2009, to June 30, 2009, of descriptive clinical course, inpatient mortality, financial data, and demographic characteristics of an ICU cohort. A case-control study was used to compare the ICU cohort to Salt Lake County residents. Results: The ICU cohort of 47 influenza patients had a median age of 34 years, Acute Physiology and Chronic Health Evaluation II score of 21 , and BMI of $35 \mathrm{~kg} / \mathrm{m}^{2}$. Mortality was $17 \%$ (8/47). All eight deaths occurred among the $64 \%$ of patients $(n=30)$ with ARDS, $26(87 \%)$ of whom also developed multiorgan failure. Compared with the Salt Lake County population, patients with novel $\mathrm{A}(\mathrm{H} 1 \mathrm{N1})$ were more likely to be obese $(22 \% \mathrm{vs} 74 \% ; P<.001)$, medically uninsured $(14 \% \mathrm{vs}$ $45 \% ; P<.001)$, and Hispanic $(13 \%$ vs $23 \% ; P<.01)$ or Pacific Islander $(1 \%$ vs $26 \% ; P<.001)$. Observed ICU admissions were 15-fold greater than expected for those with BMI $\geq 40 \mathrm{~kg} / \mathrm{m}^{2}$ (standardized morbidity ratio 15.8, 95\% CI, 8.3-23.4) and 1.5-fold greater than expected among those with BMI of 30 to $39 \mathrm{~kg} / \mathrm{m}^{2}$ for age-adjusted and sex-adjusted rates for Salt Lake County. Conclusions: Severe ARDS with multiorgan dysfunction in the absence of bacterial infection was a common clinical presentation. In this cohort, young nonwhites without medical insurance were disproportionately likely to require ICU care. Obese patients were particularly susceptible to critical illness due to novel $\mathrm{A}(\mathrm{H} 1 \mathrm{N1})$ infection.

CHEST 2010; 137(4):752-758
\end{abstract}

Abbreviations: ALI = acute lung injury; APACHE II = Acute Physiology and Chronic Health Evaluation II; CDC $=$ Centers for Disease Control and Prevention; IQR=interquartile range; novel A(H1N1)= novel 2009 influenza A(H1N1); $\mathrm{OR}=$ odds ratio; $\mathrm{SMR}=$ standardized morbidity ratio; SOFA = Sequential Organ Failure Assessment

A n outbreak of novel respiratory infection was identified in Mexico in late March 2009. On April 15, 2009, novel 2009 influenza A(H1N1) [novel A(H1N1)] was confirmed in a patient from California. ${ }^{1,2}$ An international pandemic was declared by the World

Manuscript received October 26, 2009; revision accepted November 13, 2009.

Affiliations: From the Division of Pulmonary and Critical Medicine (Drs Miller, Brown, Grissom, Hirshberg, and Dean) and the Department of Clinical Epidemiology and Infectious Diseases (Dr Dascomb), Intermountain Medical Center, Murray; the Division of Respiratory, Critical Care, and Occupational Pulmonary Medicine (Drs Miller, Markewitz, Brown, Grissom, Hirshberg, Conklin, Paine, and Dean) and the Divisions of Epidemiology and Infectious Diseases (Dr Mayer), University of Utah Health Sciences Center, Salt Lake City; and the Utah Department of Health (Dr Rolfs and Mr Friedrichs), Salt Lake City, UT.
Health Organization on June 11, 2009. As of August 18,2009 , there were 7,511 hospitalized cases of novel

For editorial comment see page 745

$\mathrm{A}(\mathrm{H} 1 \mathrm{~N} 1)$ in the United States and its territories, of which 300 hospitalized cases and 17 deaths occurred in Utah. ${ }^{3}$

Correspondence to: Russell R. Miller III, MD, MPH, Intermountain Medical Center, T4S, Respiratory Intensive Care Unit, 5121 S Cottonwood St, Murray, UT 84107; e-mail: Russ.Miller@ imail.org

(C) 2010 American College of Chest Physicians. Reproduction of this article is prohibited without written permission from the American College of Chest Physicians (www.chestpubs.org/ site/misc/reprints.xhtml).

DOI: $10.1378 /$ chest.09-2517 
Seven (39\%) of 18 initial cases of confirmed novel $\mathrm{A}(\mathrm{H} 1 \mathrm{~N} 1)$ requiring hospital admission in Mexico City ${ }^{4}$ progressed to ARDS. Global reports have subsequently provided insight into some features of severe confirmed, probable, or suspected $\mathrm{A}(\mathrm{H} 1 \mathrm{~N} 1)$ infection in the ICU, with $14 \%$ to $41 \%$ mortality and obesity prevalent in $18 \%$ to $36 \%$ of ICU patients. ${ }^{5-8}$

Salt Lake County experienced a concentrated number of severe novel $\mathrm{A}(\mathrm{H} 1 \mathrm{~N} 1)$ infections. We report the clinical presentation, ICU course, and demographic characteristics of the first 47 cases of confirmed novel $\mathrm{A}(\mathrm{H} 1 \mathrm{~N} 1)$ infection requiring ICU admission in Salt Lake County.

\section{Materials AND Methods}

Individuals with confirmed novel A(H1N1) who were older than 15 years and treated in four ICUs at three academic hospitals in Salt Lake County, Utah, from May 19, 2009, to June 30, 2009, were included in this report. We identified patients concurrently and reviewed medical charts, radiologic and laboratory findings, hospital billing charges, length of stay, and in-hospital survival. The report was declared exempt by the institutional review boards of Intermountain Healthcare and the University of Utah.

Testing

Initially, screening for novel $\mathrm{A}(\mathrm{H} 1 \mathrm{~N} 1)$ was performed with the Binax NOW Influenza A+B screen (Inverness Medical Innovations, Inc.; Waltham, MA). As more cases were identified, we noted a low sensitivity of this test for the novel strain $(31 \%$, or 12 of 39 samples positive). This prompted physicians to use other testing methodologies such as direct fluorescent antibody or multiplex polymerase chain reaction as an initial tool for hospitalized patients. All patients were confirmed by strain-specific polymerase chain reaction ${ }^{9}$ performed at the Salt Lake Valley Health Department or the Centers for Disease Control and Prevention (CDC).

\section{Definitions}

Organ failure or dysfunction was assessed daily during ICU stay according to the Sequential Organ Failure Assessment (SOFA) score $^{10}$ and at ICU admission using Acute Physiology and Chronic Health Evaluation II (APACHE II). ${ }^{11}$ Respiratory failure was further characterized as either ARDS or acute lung injury (ALI) according to consensus definitions, ${ }^{12}$ with ARDS and ALI cutoffs for $\mathrm{PaO}_{2} / \mathrm{FIO}_{2}$ ratios of 170 and 255, respectively, adjusted for Salt Lake County's average elevation $(1,400 \mathrm{~m})$. Obesity was defined as BMI 30 to $39 \mathrm{~kg} / \mathrm{m}^{2}$ and morbid obesity as BMI $\geq 40 \mathrm{~kg} / \mathrm{m}^{2}$. We classified medical insurance as one of three mutually exclusive groups at hospital admission: public (Medicare, Medicaid, or Children's Health Insurance Program), private (any form of nongovernmental insurance), or none.

\section{Statistical Analysis}

Central tendencies were compared among patient groups using Fisher exact test, Student $t$ test, or Wilcoxon rank-sum test, as appropriate. Univariate logistic regression was used to determine odds ratios (OR) and 95\% CIs for death or development of ARDS. We performed linear regression of ICU and hospital length of stay by BMI. R software, version 2.9.1 (R Foundation for Statistical Computing; Vienna, Austria), was used for statistical analyses of clinical data.

Salt Lake County demographics were obtained from the US Census Bureau, 2007. Categories of BMI $(<30,30-39$, and $\geq 40 \mathrm{~kg} / \mathrm{m}^{2}$ ) were obtained from the Utah Behavioral Risk Factor Surveillance System ${ }^{13}$ using SAS-callable SUDAAN, version 10.0.0 (SAS Institute; Cary, NC). Analyses comparing age, sex, BMI, and race/ethnicity of the study cohort with Salt Lake County were performed using Fisher exact tests in SAS version 9.2 (SAS Institute).

A standardized morbidity ratio (SMR) ${ }^{14}$ with $95 \%$ CI was calculated as the number of observed ICU cases in each BMI group divided by the expected number, given Salt Lake County population's distribution of age, sex, and BMI (see the online supplement). $P$ values for all statistical analyses were two sided with $P<.05$ considered significant.

\section{RESULTS}

\section{Clinical Data}

Forty-seven patients with novel $\mathrm{A}(\mathrm{H} 1 \mathrm{~N} 1)$ infection were admitted to one of four adult ICUs among three academic hospitals between May 19, 2009, and June 30,2009 . The median age of patients was 34 years (range 15-62 years) (Table 1). Twenty (43\%) were men. Most had typical influenza symptoms on illness presentation, including fever (100\%), cough (89\%), and shortness of breath (66\%). Sixty-two percent had one or more risk factors for influenza-related complications as defined by the CDC. ${ }^{15}$ The most common factors included asthma $(n=14)$ and diabetes $(n=8)$. Four patients were pregnant or immediately post partum. Fourteen patients were smokers, including four without established risk factors.

On admission, cohort patients were critically ill (Tables 1, 2). The median APACHE II score was 21 (interquartile range [IQR] 14-26). All had gas exchange abnormalities on admission. ARDS was diagnosed in $64 \%$ and ALI (without ARDS) in an additional $15 \%$. Seven presented with exacerbations of underlying chronic medical conditions (eg, COPD, heart failure).

Organ dysfunctions or failures were common in the early ICU course (Table 1), as reflected by high median SOFA scores on day 1 and day 2. Common organ failures included respiratory (91\%), brain (49\%), and cardiovascular (34\%) failure. Six patients (13\%) developed renal failure in the first $48 \mathrm{~h}$. Four of the six had a creatine kinase $>5,000$ units/L. An additional 13 patients developed renal failure after the first $48 \mathrm{~h}$ of ICU stay, of whom seven received continuous renal replacement therapy.

Clinical evidence of bacterial infection on ICU admission was present in six of 47 patients (13\%). Of the six patients with concomitant bacterial infection, the following clinical microbiology was noted: (1) one previously healthy patient with a blood culture and a tracheal aspirate positive for group A Streptococcus; (2) one patient with known chronic heart and lung disease as well as diabetes with blood BAL cultures positive for methicillin-resistant Staphylococcus aureus; (3) one patient with a sputum culture positive 
Table 1-Demographic and Medical Characteristics for 47 Patients With Novel A(H1N1) Virus Admitted to Four ICUs in Salt Lake County

\begin{tabular}{|c|c|}
\hline Characteristics & $\begin{array}{l}\mathrm{A}(\mathrm{H} 1 \mathrm{~N} 1) \text { Cohort } \\
\quad(\mathrm{N}=47)\end{array}$ \\
\hline \multicolumn{2}{|l|}{ Admission characteristic } \\
\hline Median age, $\mathrm{y}$ (range) & $34(15-62)$ \\
\hline Female sex, No. (\%) & $27(57)$ \\
\hline White, non-Hispanic, No. (\%) & $22(47)$ \\
\hline Median APACHE II score (IQR) & $21(14-26)$ \\
\hline \multicolumn{2}{|l|}{ Median SOFA score (IQR) } \\
\hline Day 1 & $7(3-8)$ \\
\hline Day $2^{a}$ & $6(2-8)$ \\
\hline Median leukocyte count, cells/ $\mu \mathrm{L}$ (IQR) & $6,600(5,100-9,600)$ \\
\hline $\begin{array}{c}\text { Median absolute lymphocyte count, } \\
\text { cells/ } \mu \mathrm{L}(\mathrm{IQR})\end{array}$ & $600(400-900)$ \\
\hline \multicolumn{2}{|l|}{ ICU course, first $48 \mathrm{~h}$} \\
\hline Respiratory failure, ${ }^{b}$ No. (\%) & $37(79)$ \\
\hline ARDS, No. (\%) & $30(64)$ \\
\hline Median lowest $\mathrm{PaO}_{2} / \mathrm{FIO}_{2}$ ratio (IQR) & $61(52-100)$ \\
\hline ALI, No. $(\%)$ & $7(15)$ \\
\hline Median lowest $\mathrm{PaO}_{2} / \mathrm{FIO}_{2}$ ratio (IQR) & $201(177-235)$ \\
\hline No severe respiratory disease, No. (\%) & $10(21)$ \\
\hline Median lowest $\mathrm{PaO}_{2} / \mathrm{FIO}_{2}$ ratio (IQR) & $254(190-323)$ \\
\hline Brain failure, ${ }^{\mathrm{c}}$ No. $(\%)$ & $23(49)$ \\
\hline Cardiovascular failure, ${ }^{\mathrm{c}}$ No. $(\%)$ & $16(34)$ \\
\hline Hematologic failure, ${ }^{\mathrm{c}}$ No. $(\%)$ & $7(15)$ \\
\hline Renal failure, ${ }^{\mathrm{c}}$ No. $(\%)$ & $6(13)$ \\
\hline Liver failure, ${ }^{\mathrm{c}}$ No. (\%) & $5(11)$ \\
\hline
\end{tabular}

ALI = acute lung injury; APACHE II = Acute Physiology and Chronic Health Evaluation II; IQR = interquartile range; novel $\mathrm{A}(\mathrm{H} 1 \mathrm{~N} 1)=$ novel 2009 influenza $\mathrm{A}(\mathrm{H} 1 \mathrm{N1})$; SOFA = Sequential Organ Failure Assessment.

aNine patients were excluded because they were discharged from the ICU within $24 \mathrm{~h}$.

bARDS and ALI, as defined by the American-European Consensus Conference. ${ }^{12}$ Almost all patients were on supplemental oxygen when these values were obtained. Only one patient with no severe respiratory disease had a missing arterial blood gas for determination of the lowest $\mathrm{PaO}_{2} / \mathrm{FIO}_{2}$ ratio.

cDefined as SOFA score $\geq 2$ for each component organ failure.

for Pseudomonas aeruginosa (mucoid); this patient had known bronchiectasis and prior pseudomonal colonization; (4) one patient (a known smoker with hypertension) with a tracheal aspirate positive for Haemophilus influenzae; (5) one previously healthy pregnant female with tracheal aspirate positive for methicillin-sensitive Staphylococcus aureus; and (6) one patient with known asthma and illicit drug abuse with methicillin-sensitive Staphylococcus aureus bacteremia, without echocardiographic or other clinical evidence of endocarditis. Only the patient with group A Streptococcus sepsis died during hospitalization; death occurred within $6 \mathrm{~h}$ of ICU admission. All other patients with known bacterial infections (five of six) survived to hospital discharge.

\section{ARDS Cohort}

Sixty-four percent $(\mathrm{n}=30)$ of the cohort developed ARDS with a median APACHE II score of
Table 2-Radiographic Results on Admission and Within $48 \mathrm{H}$ of ICU Admission Among 47 Patients With Novel A(H1N1) Admitted to Four ICUs in Salt Lake County

\begin{tabular}{lc}
\hline \hline Radiograph Results & $\mathrm{A}(\mathrm{H} 1 \mathrm{~N} 1)$ Cohort $(\mathrm{N}=47)$ \\
\hline Admission chest radiograph & \\
Infiltrate(s), No. (\%) & $42(89)$ \\
Bilateral & $39(93)$ \\
Unilateral & $3(9)$ \\
Chest radiographs within first $48 \mathrm{~h}$ & \\
Infiltrate(s), No. (\%) & $43(91)$ \\
Bilateral & $41(95)$ \\
Unilateral & $2(5)$
\end{tabular}

For all chest radiographs, the corresponding official radiologist's interpretation was used to determine the presence and location (ie, unilateral or bilateral, if present) of pulmonary infiltrates. See Table 1 for expansion of abbreviation.

25 (IQR 21-35). Eight ARDS patients died. Severe gas exchange abnormalities were documented by low ratio of arterial oxygen pressure to fraction of inspired oxygen $(\mathrm{n}=30)$ (Table 1), decreased dynamic thoracic compliance ( $\mathrm{n}=25$, median 22, IQR 21-34 $\mathrm{mL} / \mathrm{cm} \mathrm{H}_{2} \mathrm{O}$ ), and high positive end-expiratory pressure $(\mathrm{n}=25$, median 22, IQR $11-25 \mathrm{~cm} \mathrm{H}_{2} \mathrm{O}$ ) in the first $48 \mathrm{~h}$. Fourteen patients $(47 \%)$ with ARDS had positive end-expiratory pressure $\geq 20 \mathrm{~cm} \mathrm{H}_{2} \mathrm{O}$, all with $\mathrm{FIO}_{2}$ of $100 \%$. Twenty-six of 30 patients with ARDS (87\%) developed at least one other organ dysfunction, with median SOFA score of 8 (IQR 7-13) on day $1(n=30)$ and 8 (IQR $5-13)$ on day $2(\mathrm{n}=29$, excluding one patient who died $<24 \mathrm{~h}$ after ICU admission); $23 \%$ had four or more organ failures.

ARDS survivors required mechanical ventilation for a median of 7.6 (IQR 1.6-16.0) days. Thirteen ARDS patients initially received noninvasive positive pressure ventilation, but 11 of these were endotracheally intubated within a median of 7.9 (IQR 2.820.8) h. Fifty-five percent of ARDS patients received steroids for shock $(\mathrm{n}=5)$, asthma $(\mathrm{n}=4)$, fetal lung development $(\mathrm{n}=1)$, postextubation stridor $(\mathrm{n}=1)$, and profound hypoxemia $(\mathrm{n}=1)$. No patient received "rescue therapy" for ARDS, such as inhaled nitric oxide, extracorporeal membrane oxygenation, prone positioning, inhaled epoprostenol, or high-frequency oscillatory ventilation. However, $47 \%$ (14 of 30 ) received paralysis for $\geq 2 \mathrm{~h}$. Intubated patients initially received either pressure-support ventilation or a targeted tidal volume of $6 \mathrm{~mL} / \mathrm{kg}$ with pressureregulated volume control or assist-control ventilation.

ARDS survivors had longer ICU (median 8.8, IQR 5.0-19.8 vs median 1.1, IQR 0.7-1.8) and hospital (median 13.9, IQR 9.6-25.0 vs median 3.5, IQR 2.94.9) stays than non-ARDS patients (both $P<.001$ ). In univariate analyses, APACHE II score on ICU admission (OR 1.3; $P<.01)$ and non-Pacific Islander race (OR 10.1; $P<.01)$ were associated with ARDS. 


\section{Survival}

Thirty-nine (83\%) patients survived to hospital discharge. A higher APACHE II score was associated with mortality $(P<.05)$. Patients first admitted to an outside ICU $(n=9)$ accounted for six of eight deaths. Transferred patients were more likely to die than nontransferred patients $(\mathrm{n}=38, P<.001)$ and had higher APACHE II scores $(P=.08)$.

All eight patients who died had ARDS, and all were obese; two were morbidly obese. Two had known cirrhosis; one died of unremitting shock and hypoxemia not of bacterial origin; three had severe hypoxic or anoxic brain injury diagnosed on admission to the ICU by clinical examination, brain imaging, and/or electroencephalography; one died of group A streptococcal septicemia within $6 \mathrm{~h}$ of ICU admission; and one patient $>60$ years old had support withdrawn because she directed no ventilation beyond 7 days.

\section{Antimicrobial Treatment}

No patient received oseltamivir prior to hospital admission. All but two patients received oseltamivir within $24 \mathrm{~h}$ of admission. Median time to oseltamivir therapy from onset of fever was 3 days (IQR 1-4). Ninety-four percent overall, and all ARDS/ALI patients, received broad-spectrum antibiotics on hospital admission, continued for a median of 6 days (IQR 4-8).

\section{Demographic Comparison with County Population}

Demographics of the study population are compared with Salt Lake County residents $\geq 15$ years old in Table $3 .{ }^{16}$ The study patients' median age was similar to the county residents' median age, 34 years and 30 years, respectively $(P>.05)$. However, when evaluated by age group, the ICU patients had a higher proportion of 15 - to 24 -year olds ( $32 \%$ vs $20 \%$, respectively, $P<.001$, Table 3$)$. The cohort also had proportionally more Pacific Islanders $(26 \%$ vs $1 \%, P<.001)$ and white Hispanics $(23 \%$ vs $13 \%, P<.01)$. An examination by zip code demonstrated that our cohort resided in geographically divergent parts of the county.

In striking contrast to the general county population, critically ill patients with novel $\mathrm{A}(\mathrm{H} 1 \mathrm{~N} 1)$ were more likely to be uninsured than the general county population (unpublished data, 2008 Utah Healthcare Access Survey) (45\% vs $14 \% ; P<.001)$. Patients in our cohort were also more likely to have public insurance $(21 \%$ vs $9 \% ; P<.01)$ and less likely to have private insurance $(34 \%$ vs $78 \% ; P<.001)$ than the county population.

\section{BMI Comparison}

Our cohort had significantly higher odds of obesity and morbid obesity than the Salt Lake County popu- lation (Table 3). Observed ICU admissions were 1.4-fold higher than expected based on age- and sexadjusted rates for the Salt Lake County population with BMI of 30 to $39 \mathrm{~kg} / \mathrm{m}^{2}$ (SMR 2.4, 95\% CI 1.3-3.5). Observed ICU admissions were 14.8-fold greater than expected based on age- and sex-adjusted rates for $B M I \geq 40 \mathrm{~kg} / \mathrm{m}^{2}$ (SMR 15.8, 95\% CI 8.3-23.4). There was no difference in ICU length of stay or hospital length of stay by BMI. This is in contrast to the findings of McCallister et $\mathrm{al}^{17}$ and Gong et $\mathrm{a}^{18}$ for obese patients with ARDS not due to novel $\mathrm{A}(\mathrm{H} 1 \mathrm{~N} 1)$ infection. Because all patients who died were obese or morbidly obese, statistical analysis of obesity as a predictor of mortality was precluded. To control for potential confounding between race/ethnicity and obesity, we reconducted analyses in a population restricted by separately excluding Pacific Islanders, Hispanics, patients $<18$ years old, and nonresidents of Salt Lake County; these exclusions did not alter statistical inferences.

\section{DISCUSSION}

This case series reveals the spectrum of critical illness among a young cohort with severe ARDS and multiorgan dysfunction solely attributable to novel $\mathrm{A}(\mathrm{H} 1 \mathrm{N1})$ infection seen during a 6 -week period in Salt Lake County. We also report demographic features in our ICU cohort (race/ethnicity, BMI, and medical insurance) compared with the Salt Lake County population.

Severe infection from influenza typically occurs in the elderly, the very young, and those with comorbid diseases. ${ }^{19}$ Consistent with findings reported elsewhere, ${ }^{5-8}$ patients with critical illness in our cohort were adults younger than expected for seasonal influenza. ${ }^{20}$ Novel $\mathrm{A}(\mathrm{H} 1 \mathrm{~N} 1)$ infection resulted in severe hypoxemia and multiorgan dysfunction without concomitant bacterial infection in our ICU patients, similar to findings from other reports on novel A(H1N1)5-8 but contradicting what is known of the 1918-1919 pandemic. $^{20}$

Importantly, severity of illness and mortality in our cohort are similar to those demonstrated previously with novel A(H1N1) despite not using "rescue therapies" for severe hypoxemia. Compared with the Australia and New Zealand novel A(H1N1) experience, ${ }^{21}$ where hospital mortality among ARDS patients selected to receive extracorporeal membrane oxygen was $23 \%$, hospital mortality among similarly ill ARDS patients in our cohort who received usual care for ARDS (ie, low tidal volume, low pressure ventilation) was $27 \%$. One-half of our mortality occurred in patients who would not have been offered extracorporeal membrane oxygenation or other "rescue therapies": one 
Table 3-Demographics for the ICU A(H1N1) Cohort Compared With 2007 Salt Lake County Census Data16 for Patients $\geq 15$ Years Old

\begin{tabular}{|c|c|c|c|c|}
\hline Characteristic & $\begin{array}{c}\mathrm{A}(\mathrm{H} 1 \mathrm{~N} 1) \\
\text { Cohort }(\mathrm{N}=47)\end{array}$ & $\begin{array}{l}\text { Salt Lake County } \\
\qquad(\mathrm{N}=767,683)\end{array}$ & Odds Ratio & $P$ Value \\
\hline \multicolumn{5}{|l|}{ Age, No. $(\%)$} \\
\hline$\geq 45 \mathrm{y}$ & $14(30)$ & $307,266(40)$ & Referent & \\
\hline $35-44 y$ & $8(17)$ & $139,349(18)$ & 1.3 & .65 \\
\hline $25-34 y$ & $10(21)$ & $165,315(22)$ & 1.3 & .52 \\
\hline $15-24 y$ & $15(32)$ & $155,753(20)$ & 2.1 & .05 \\
\hline \multicolumn{5}{|l|}{ Sex, No. $(\%)$} \\
\hline Male & $20(43)$ & $389,096(51)$ & Referent & \\
\hline Female & $27(57)$ & $378,587(49)$ & 1.4 & .31 \\
\hline \multicolumn{5}{|l|}{ Race/ethnicity, No. (\%) } \\
\hline White, non-Hispanic & $22(47)$ & $605,533(79)$ & Referent & \\
\hline White, Hispanic & $11(23)$ & $106,801(13)$ & 2.8 & .01 \\
\hline Asian & $1(2)$ & $26,402(3)$ & 1.0 & .38 \\
\hline Pacific Islander/Native Hawaiian & $12(26)$ & $11,055(1)$ & 29.9 & $<.001$ \\
\hline Black & $1(2)$ & $10,104(1)$ & 2.7 & .32 \\
\hline American Indian/Alaskan Native & $0(0)$ & $7,788(1)$ & NA & NA \\
\hline \multicolumn{5}{|l|}{ BMI, No. $(\%)$} \\
\hline$<30 \mathrm{~kg} / \mathrm{m}^{2}$ & $12(26)$ & $605,702(79)$ & Referent & \\
\hline $30-39 \mathrm{~kg} / \mathrm{m}^{2}$ & $18(38)$ & $142,021(19)$ & 6.4 & $<.001$ \\
\hline$\geq 40 \mathrm{~kg} / \mathrm{m}^{2}$ & $17(36)$ & $19,960(3)$ & 43.0 & $<.001$ \\
\hline
\end{tabular}

because of demise from group A streptococcal sepsis within $6 \mathrm{~h}$ postadmission, and three because of severe hypoxic brain injury at ICU admission. Therefore, mortality in our cohort compared favorably with centers where "rescue therapies" were used. .-8 $^{-8}$

Unexpectedly, our novel A(H1N1) cohort was more likely to be Pacific Islander or Hispanic compared with the Salt Lake County population. Several hypotheses should be considered. First, obesity may contribute to severe disease and may be more common in identified racial/ethnic groups in our community. Exclusion of patients of these races/ethnicities, however, did not alter the statistically significant relationship between obesity and ICU admission. Second, ethnic communities may have had an epidemic spread of novel $\mathrm{A}(\mathrm{H} 1 \mathrm{~N} 1)$. Two patients presenting to our facilities were from a common community group, in which several members developed influenza-like illness. Third, Hispanics or Pacific Islanders may have a genetic predisposition for a more severe manifestation of $\mathrm{A}(\mathrm{H} 1 \mathrm{~N} 1)$ infection. Finally, race/ethnicity, lack of medical insurance, and younger age may be related to less access to care, such that socioeconomic factors, rather than genetic predisposition, may be responsible for severe disease due to novel $\mathrm{A}(\mathrm{H} 1 \mathrm{~N} 1)$ infection. Additional, targeted investigations are required to determine the influence of socioeconomic factors on our results.

Obese patients in our cohort were more likely to be admitted to the ICU with novel A(H1N1) infection than expected among the general population, similar to the observations from Australia and New Zealand.22 Additionally, we noted that the morbidly obese were at marked increased risk of critical illness. Obesity was associated with ICU admission even after adjustment for other demographic variables. Interestingly, 13 of 18 patients (72\%) in our cohort without comorbid factors as described by the CDC were obese or morbidly obese.

An early 2009 metaanalysis indicated that obesity was not associated with increased ICU mortality. A recent, large cohort study by Gong et al, ${ }^{18}$ prior to the novel $\mathrm{A}(\mathrm{H} 1 \mathrm{~N} 1)$ infection, noted an association of obesity with ARDS but not with mortality. The Canadian novel $\mathrm{A}(\mathrm{H} 1 \mathrm{~N} 1)$ experience likewise suggests that BMI did not differ between survivors and nonsurvivors. ${ }^{7}$ Because all patients who died in our cohort were obese or morbidly obese, statistical analysis of obesity by survival was precluded.

Our novel $\mathrm{A}(\mathrm{H} 1 \mathrm{~N} 1)$ cohort was more likely to be medically uninsured than the county population. Costly care for the uninsured with novel A(H1N1) will burden hospitals financially. Critically ill patients with novel A(H1N1) infection will create substantial hospital charges, exceeding $\$ 4$ million in our cohort. The high percentage of uninsured individuals in this critically ill cohort has important implications for future waves of $\mathrm{A}(\mathrm{H} 1 \mathrm{~N} 1)$ infection. We recommend strategies to make antiviral medications available to the uninsured who qualify for treatment, and the promotion of vaccination among the obese.

Several limitations of our investigation make our epidemiologic findings suggestive rather than definitive. First, all patients came from one Utah county. Although we enrolled almost all $(\mathrm{N}=47)$ adult patients critically ill with novel $\mathrm{A}(\mathrm{H} 1 \mathrm{~N} 1)$ infection 
in the county during the period $(\mathrm{N}=51$, unpublished report, Utah Department of Health), our sample size was too small for multivariable analyses. Second, we had no ideal control group for statistical comparison of cases. Because we were in the midst of an epidemic, all persons in the county were susceptible although few were being tested. Selection of another control, such as hospitalized patients ${ }^{23}$ or outpatients, was impeded by inconsistent testing; the denominator would have included both confirmed novel $\mathrm{A}(\mathrm{H} 1 \mathrm{~N} 1)$ cases and those of other, undiagnosed influenza-like illness. Third, the Behavioral Risk Factor Surveillance Study supporting the determination of obesity in the county relies on self-reported height and weight from drivers' licenses. However, assuming up to a $15 \%$ underestimation of actual BMI (due either to overreporting of height or underreporting of weight) our finding of increased risk associated with obesity remained statistically consistent.

\section{ConClusions}

We report a critically ill cohort with unexpected numbers of nonwhite, obese, medically uninsured patients with novel $\mathrm{A}(\mathrm{H} 1 \mathrm{~N} 1)$ infection, most with severe lung injury and multiorgan dysfunction due to influenza without concomitant bacterial infection. Our findings suggest that demographic factors and obesity are associated with critical illness due to novel $\mathrm{A}(\mathrm{H} 1 \mathrm{~N} 1)$ infection.

\section{ACKNOWLEDGMENTS}

Author contributions: Dr Miller: contributed to collecting data and drafting and revising the submitted manuscript.

Dr Markewitz: contributed to collecting data and drafting and revising the submitted manuscript.

Dr Rolfs: contributed to collecting data and drafting and revising the submitted manuscript.

Dr Brown: contributed to drafting and revising the submitted manuscript.

Dr Dascomb: contributed to drafting and revising the submitted manuscript.

Dr Grissom: contributed to drafting and revising the submitted manuscript.

Mr Friedrichs: contributed to collecting data and drafting and revising the submitted manuscript.

Dr Mayer: contributed to drafting and revising the submitted manuscript.

Dr Hirshberg: contributed to drafting and revising the submitted manuscript.

Dr Conklin: contributed to collecting data and revising the submitted manuscript.

Dr Paine: contributed to drafting and revising the submitted manuscript.

Dr Dean: contributed to collecting data and drafting and revising the submitted manuscript.

Financial/nonfinancial disclosures: The authors have reported to CHEST the following conflicts of interest: As Utah State Epidemiologist, Dr Rolfs makes public statements and recommendations about influenza and other public health concerns. The opinions expressed in this article are those of the authors and do not necessarily represent the views of the Utah Department of
Health. The other authors have reported to CHEST that no potential conflicts of interest exist with any companies/organizations whose products or services may be discussed in this article.

Other contributions: The authors thank the faculty and staff of the Respiratory ICU, Shock-Trauma ICU, and Infection Control at Intermountain Medical Center; the Medical-Surgical ICU at LDS Hospital; and the Medical ICU at the University of Utah for their tireless and skillful efforts caring for these patients. We acknowledge Drs Mark Goddard and Ramona Hopkins for critical review of earlier drafts of the manuscript, Ms Larissa Rodriguez for database assistance, and Ms Kimberly McNamara for Salt Lake County data in this manuscript.

\section{REFERENCES}

1. Dawood FS, Jain S, Finelli L, et al; Novel Swine-Origin Influenza A (H1N1) Virus Investigation Team. Emergence of a novel swine-origin influenza A (H1N1) virus in humans. N Engl J Med. 2009;360(25):2605-2615.

2. Centers for Disease Control and Prevention (CDC). Swine influenza A (H1N1) infection in two children-Southern California, March-April 2009. MMWR Morb Mortal Wkly Rep. 2009;58(15):400-402.

3. Utah Department of Health. Influenza 2009-2010 Utah public health situation report 08/19/2009. http://health.utah.gov/ epi/h1n1flu/. Accessed September 22, 2009.

4. Perez-Padilla R, de la Rosa-Zamboni D, Ponce de Leon S, et al; INER Working Group on Influenza. Pneumonia and respiratory failure from swine-origin influenza A (H1N1) in Mexico. N Engl J Med. 2009;361(7):680-689.

5. Rello J, Rodríguez A, Ibañez P, et al; the H1N1 SEMICYUC working group. Intensive care adult patients with severe respiratory failure caused by Influenza $\mathrm{A}(\mathrm{H} 1 \mathrm{~N} 1) \mathrm{v}$ in Spain. Crit Care. 2009;13(5):R148.

6. Jain S, Kamimoto L, Bramley AM, et al; 2009 Pandemic Influenza A(H1N1) Virus Hospitalizations Investigation Team. Hospitalized patients with $2009 \mathrm{H} 1 \mathrm{N1}$ influenza in the United States, April-June 2009. N Engl J Med. 2009;361(20):1935-1944.

7. Kumar A, Zarychanski R, Pinto R, et al. Critically ill patients with 2009 influenza $\mathrm{A}(\mathrm{H} 1 \mathrm{~N} 1)$ infection in Canada. JAMA. 2009;302(17):1872-1879.

8. Dominguez-Cherit G, Lapinsky SE, Macias AE, et al. Critically ill patients with 2009 influenza A(H1N1) in Mexico. JAMA. 2009;302(17):1880-1887.

9. CDC protocol of realtime RTPCR for influenza A (H1N1). Geneva: World Health Organization, April 2009. http://www. who.int/csr/resources/publications/swineflu/CDCRealtime RTPCR_SwineH1Assay-2009_20090430.pdf. Accessed July 21,2009

10. Vincent JL, de Mendonça A, Cantraine F, et al. Use of the SOFA score to assess the incidence of organ dysfunction/ failure in intensive care units: results of a multicenter, prospective study. Working group on "sepsis-related problems" of the European Society of Intensive Care Medicine. Crit Care Med. 1998;26(11):1793-1800.

11. Knaus WA, Draper EA, Wagner DP, Zimmerman JE. APACHE II: a severity of disease classification system. Crit Care Med. 1985;13(10):818-829.

12. Bernard GR, Artigas A, Brigham KL, et al. The AmericanEuropean Consensus Conference on ARDS. Definitions, mechanisms, relevant outcomes, and clinical trial coordination. Am J Respir Crit Care Med. 1994;149(3 Pt 1):818-824.

13. Utah Department of Health. Office of Public Health Assessment. Utah behavioral risk factor surveillance system 2006-2008. http://health.utah.gov/opha/OPHA_BRFSS.htm. Accessed September 22, 2009.

14. Kahn HA, Sempos CT. Statistical Methods in Epidemiology. New York, NY: Oxford University Press; 1989. 
15. Fiore AE, Shay DK, Broder K, et al; Centers for Disease Control and Prevention (CDC); Advisory Committee on Immunization Practices (ACIP). Prevention and control of influenza: recommendations of the Advisory Committee on Immunization Practices (ACIP), 2008. MMWR Recomm Rep. 2008;57(RR-7): $1-60$.

16. Population Estimates Program, U.S. Bureau of the Census. http://ibis.health.utah.gov. Accessed September 22, 2009.

17. McCallister JW, Adkins EJ, O'Brien JM Jr. Obesity and acute lung injury. Clin Chest Med. 2009;30(3):495-508.

18. Gong MN, Bajwa E, Thompson BT, et al. Body mass index is associated with the development of acute respiratory distress syndrome. Thorax. 2010;65(1):44-50.

19. Falsey AR, Walsh EE. Viral pneumonia in older adults. Clin Infect Dis. 2006;42(4):518-524.
20. Morens DM, Taubenberger JK, Fauci AS. Predominant role of bacterial pneumonia as a cause of death in pandemic influenza: implications for pandemic influenza preparedness. J Infect Dis. 2008;198(7):962-970.

21. The Australia New Zealand Extracorporeal Membrane Oxygenation Influenza Investigators. Extracorporeal membrane oxygenation for 2009 Influenza A(H1N1) acute respiratory distress syndrome. JAMA. 2009;302(17):1888-1895.

22. The ANZIC Influenza Investigators. Critical care services and 2009 H1N1 influenza in Australia and New Zealand. N Engl J Med. 2009;361(20):1925-1934.

23. Louie JK, Acosta M, Winter K, et al; California Pandemic (H1N1) Working Group. Factors associated with death or hospitalization due to pandemic 2009 influenza $\mathrm{A}(\mathrm{H} 1 \mathrm{~N} 1)$ infection in California. JAMA. 2009;302(17):1896-1902 